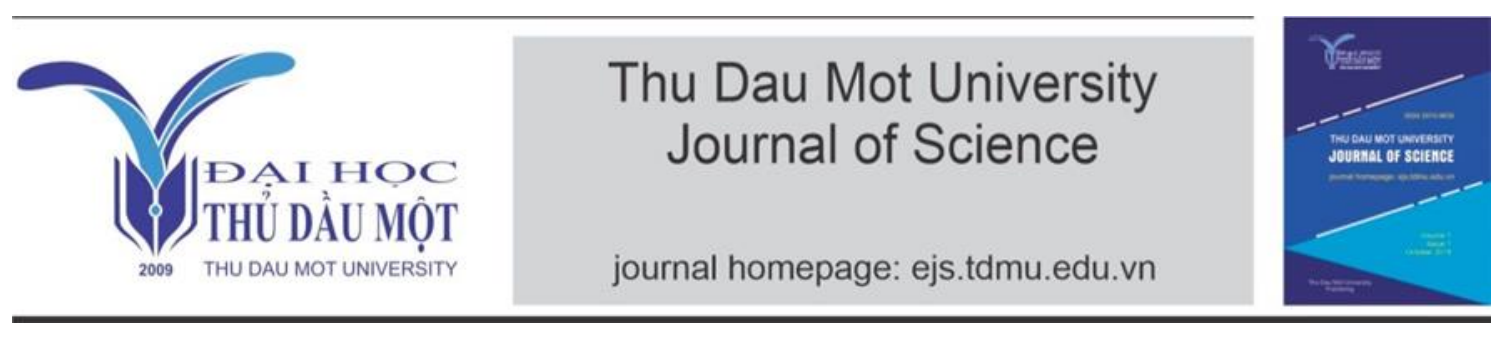

\title{
Spent coffee grounds collected in Ho Chi Minh city: A good source of phenolic acids and fatty acids
}

by Vũ Công Danh, Vũ Thị Quyền (Van Lang University)

Nguyễn Hà Diệu Trang (Industrial University of Ho Chi Minh City)

\author{
Article Info: $\quad$ Received 6 June 2021, Accepted 2 Sep 2021, Available online 15 Sep 2021 \\ Corresponding author: nguyenhadieutrang@iuh.edu.vn \\ https://doi.org/10.37550/tdmu.EJS/2021.03.211
}

\begin{abstract}
Coffee is among the favorite drinks in Vietnam and many other countries. Production and consumption of coffee have released a huge amount of spent coffee ground. This study aimed to determine phenolic acids and fatty acids of spent coffee grounds collected in Ho Chi Minh city and how phenolic acid profile was affected by different environmentally friendly extractants. The results showed that average level of chlorogenic acid in ethanol/water extracts $(840.4779 .9 \mu \mathrm{g} / \mathrm{g})$ was significantly higher compared to water extracts $(300.0 \mu \mathrm{g} / \mathrm{g})$. Furthermore, the average total level of phenolic acids in ethanol/water extracts $(1215.3 \mu \mathrm{g} / \mathrm{g}$ dry weight) was greater than that in the water extracts $(779.9 \mu \mathrm{g} / \mathrm{g}$ dry weight). This indicated that ethanol/water outperformed water in regard to extraction of phenolic acids in the spent coffee grounds. Oil extracted from the spent coffee

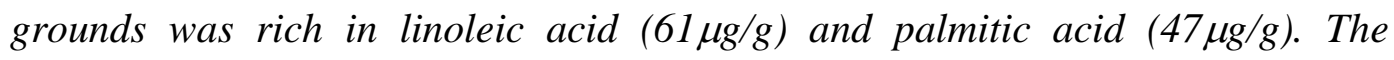
findings of our study showed that the spent coffee grounds originating in Vietnam are a good source of phenolic acids and polyunsaturated fatty acids that could be utilized for food and nutraceutical production.
\end{abstract}

Keywords: chlorogenic acid, coffee, nutraceutical, phenolic acids, spent coffee

\section{Introduction}

Coffee which is produced from seeds of the coffee plant (Coffea sp.) is one of the 
favorite drinks in the world. Coffee production accounts for a huge amount of a main byproduct called spent coffee ground (SCG), approximately 6 million tons per year (Getachew \& Chun, 2017). Research showed that oil and cellulose in SCG can be used in production of biodiesel, hydrogen, ethanol, sorbitol, mannitol, arabitol and xylitol (Kondamudi, Mohapatra, \& Misra, 2008; Mussatto, Machado, Martins, \& Teixeira, 2011). In addition, fiber, essential amino acids and aroma compounds in SCG were suitable for bakery and beverage products (Martinez-Saez et al., 2017; Sampaio et al., 2013). Phenolic compounds, such as chlorogenic and gallic acids, in SCG can be exploited as health-promoting food ingredients (Iriondo-DeHond et al., 2019).

Vietnam is the second largest coffee producing country with more than 1.6 million metric tons in 2019 (World Atlas, 2016). Domestic coffee consumption in Vietnam is about 180 thousand metric tons, equivalent to $1.68 \mathrm{~kg} / \mathrm{person}$ (Ministry of Agriculture and Rural Development, 2020). This hints at a huge amount of SCG that may have been released in the country. Previously, this byproduct is often dumped into general waste and sent to landfill from which it can emit methane, causing multiple environmental issues. To our knowledge, no approaches to valorizing SCG have been explored with respect to food and nutraceutical productions. This could be due to limited information about phytochemical composition of SCG. The aim of this study was to explore phenolic and fatty acids of SCG obtained during the brewing of Vietnamese coffee. We investigated how the use of nontoxic, inexpensive, environmentally friendly solvents affected phenolic profiles of SCG. This work will not only give a better understanding of phenolic and fatty acid compositions of SCG originating in Vietnam but also help identify new applications of SCG in food and nutraceutical industries.

\section{Materials and methods}

\subsection{Chemicals}

Phenolic standards, including gallic, cinnamic, chlorogenic, caffeic, p-coumaric, ferulic acid, 2,4-dihydroxybenzoic and salicylic acids, were purchased from Sigma-Aldrich (St. Louis, MO, USA). Methanol, ethanol, ethyl acetate and acetone were purchased from Xilong Chemical (Guangdong, China).

\subsection{Preparation of SCG extracts}

Spent coffee grounds collected from popular coffee shops in Ho Chi Minh city were pooled together and dried for about 5 hours at $45{ }^{\circ} \mathrm{C}$ to obtain a moisture $<5 \%$ (Figure 1). The dried SCG was mixed with solvents (aqueous ethanol and deionized water) at a ratio of $30 \mathrm{~g} / 100 \mathrm{ml}$. After shaken for 24 hours on a shaker, the mixtures were filtered through a Whatman filter paper, and the filtrates were injected into a high-performance liquid chromatograph (HPLC). 


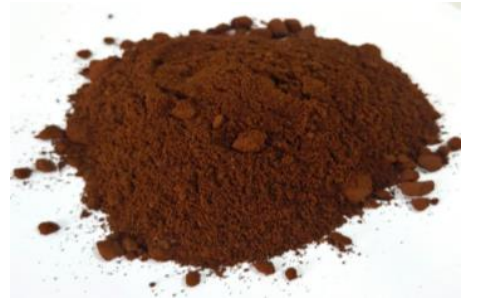

Figure 1. A photo of dried spent coffee ground collected from a coffee shop located in Ho Chi Minh city

\subsection{Determination of phenolic acids}

The analysis was carried out on a Shimadzu LC-2030C HPLC coupled to a diode-array detector (HPLC-DAD) and equipped with a VertiSep ${ }^{\mathrm{TM}}$ GES C18 reverse-phase chromatographic column $(250 \times 4.6 \mathrm{~mm}, 5.0 \mu \mathrm{m}$ particle size $)$. Methanol (A) and $1 \%$ formic acid in water $(\mathrm{B})$ were used as a mobile phase, with the composition varying as follows: 0 to $3 \mathrm{~min}, 25 \% \mathrm{~A} ; 3$ to $5 \mathrm{~min}, 25 \%$ to $40 \% \mathrm{~A} ; 5$ to $16 \mathrm{~min}, 40 \%$ to $60 \% \mathrm{~A} ; 16$ to $21 \mathrm{~min}, 60 \% \mathrm{~A} ; 21$ to $24 \mathrm{~min}, 60 \%$ to $80 \% \mathrm{~A}, 24$ to $27 \mathrm{~min}, 80 \% \mathrm{~A}, 27$ to $35 \mathrm{~min}, 80$ to $25 \% \mathrm{~A}$. The elution was performed at a flow rate of $0.8 \mathrm{~mL} / \mathrm{min}$ and the column temperature was set at $40^{\circ} \mathrm{C}$. The detection of phenolic acids was set at a wavelength of $275 \mathrm{~nm}$. Data were analyzed using LabSolutions software (Shimadzu, Kyoto, Japan). Quantification of phenolic acids was based on calibration curves constructed using five concentrations $(0.1,0.25,0.5,1,5 \mu \mathrm{g} / \mathrm{ml})$.

\subsection{Determination of fatty acids}

Oil from SCG was extracted following the technique described by Vu et al. (2019) (Vu, Lei, Sumner, Coggeshall, \& Lin, 2019). To determine fatty acids, the oil was methylated with $\mathrm{BF}_{3} /$ methanol $(1 \mathrm{ml})$ for $45 \mathrm{~min}$ at $60^{\circ} \mathrm{C}$. Analysis of fatty acids was carried out using Shimadzu gas chromatograph 2010 connected with flame ionization detector set at $280^{\circ} \mathrm{C}$. The temperature gradient was at $100-230^{\circ} \mathrm{C}$ at the rate of $7^{\circ} \mathrm{C} / \mathrm{min}$ with nitrogen as a carrier gas.

\subsection{Statistical analysis}

One-way analysis of variance (ANOVA) was carried out on the data obtained to compare phenolic levels between SCG samples. The significance difference between mean values was determined with the Tukey HSD test $(\mathrm{p}<0.05)$.

\section{Results and discussion}

\subsection{Extraction and HPLC analysis of phenolic acids}

Phenolics are a class of naturally occurring compounds that have aroused much attention due to their bioactivities of importance to human health. The analysis of phenolics in plants can be performed using liquid-solid extraction. One of the factors that are likely to have impacts on a liquid-solid extraction method is extraction solvents. 
For this reason, we evaluated the extraction of SCG phenolics using two solvents, namely EtOH/water (1:1) and deionized water. These are commonly used for extraction of SCG phenolics (Choi \& Koh, 2017; Zengin et al., 2020), and importantly, are regarded as environmentally friendly solvents. Eight phenolic acids (gallic, chlorogenic, caffeic, p-coumaric, ferulic acid, 2,4-dihydroxybenzoic, salicylic and cinnamic acids) were simultaneously screened for the SCG using HPLC-DAD. These are the phenolics which a large number of prior studies were focused on. Figure 2 displays a chromatogram of the phenolic acids in a standard solution. Table 1 shows retention times of the phenolic acids monitored. Gallic acid was the first phenolic to elute (4.93 min) while cinnamic acid was the last to come off the column (23.48 min).

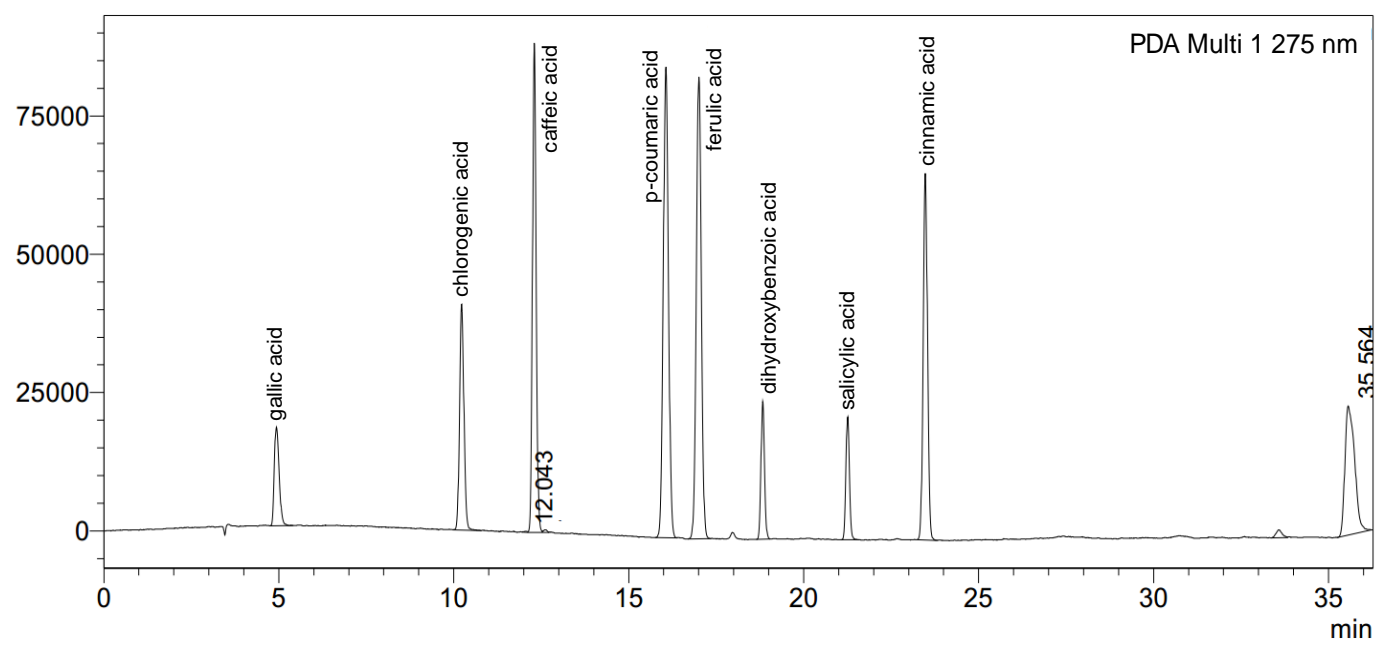

Figure 2. A HPLC-DAD chromatogram of phenolic acid standards

As seen in Table 1, we used the linear relationship to fit calibration curves over the concentration range between 0.1 and $5 \mu \mathrm{g} / \mathrm{ml}$. Figure 3 graphically displays the calibration curve for chlorogenic acid which is used to illustrate the results of calibration. The correlation coefficients $\left(\mathrm{R}^{2}\right)$ for the calibration curves are shown in Table 1, and these values are all higher than 0.99 .

TABLE 1. Retention times, calibration curves and linear correlation coefficients of the phenolic acids

\begin{tabular}{|l|c|c|c|}
\hline \multicolumn{1}{|c|}{ Compound } & Retention time, $\min$ & Linear equation & Correlation coefficient, $\mathrm{R}^{2}$ \\
\hline Gallic acid & 4.93 & $\mathrm{y}=35069.4 \mathrm{x}$ & 0.999 \\
\hline Chlorogenic acid & 10.22 & $\mathrm{y}=41527.5 \mathrm{x}$ & 0.998 \\
\hline Caffeic acid & 12.30 & $\mathrm{y}=72708.7 \mathrm{x}$ & 0.999 \\
\hline p-Coumaric acid & 16.06 & $\mathrm{y}=82326.3 \mathrm{x}$ & 0.999 \\
\hline Ferulic acid & 17.00 & $\mathrm{y}=64854.2 \mathrm{x}$ & 0.999 \\
\hline DA* & 18.83 & $\mathrm{y}=19028.0 \mathrm{x}$ & 0.999 \\
\hline Salicylic acid & 21.25 & $\mathrm{y}=20296.6 \mathrm{x}$ & 0.999 \\
\hline Cinnamic acid & 23.48 & $\mathrm{y}=140343.0 \mathrm{x}$ & 0.999 \\
\hline
\end{tabular}

*2,4-dihydroxybenzoic acid 


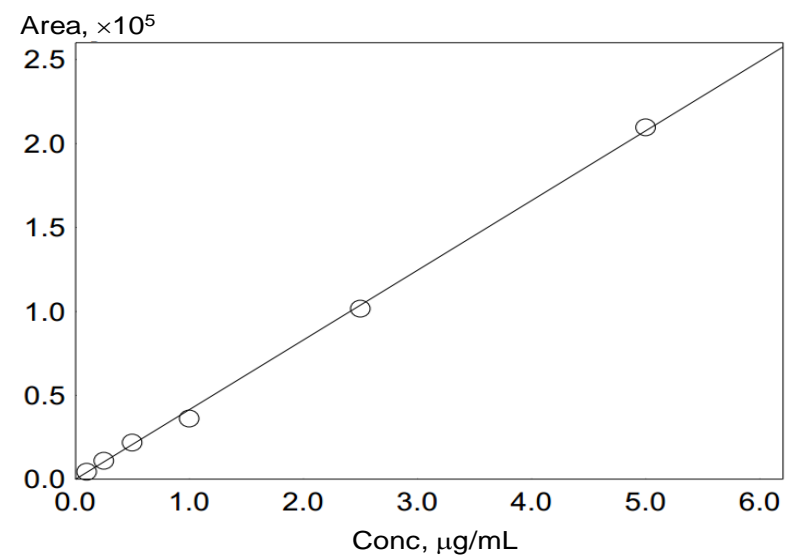

Figure 3. The calibration curve for chlorogenic acid is representative of the calibration results.

\subsection{Phenolic acids in SCG}

Table 2 shows the concentrations of the eight compounds in the SCG extracts obtained, expressed as $\mu \mathrm{g} / \mathrm{g}$ of dry weight. The results demonstrated that EtOH/water was the excellent solvent for extracting chlorogenic acid (CGA) in SCG as the concentration of this phenolic acid in the aqueous ethanolic extract $(840.4 \mu \mathrm{g} / \mathrm{g}$ dry weight) was much higher than that in the aqueous extract. EtOH/water was also a great extractant for pcoumaric, ferulic and dihydroxybenzoic acids. As shown in Table 2, the EtOH/water extract contains a significantly higher level of phenolic acids compared to the aqueous extract $(\mathrm{p}<0.05)$. Reportedly, EtOH/water performed better than water regarding extraction of phenolics in SCG and coffee silver skin (Zengin et al., 2020). Interestingly, water proved to be an efficient extractant for SCG phenolic acids, particularly CGA, caffeic and ferulic acids. For example, water was shown to possess a higher extraction capacity for caffeic acid. The caffeic acid concentration value (348 $\mu \mathrm{g} / \mathrm{g}$ dry weight) in the aqueous extract was 2.5 times higher than that in the aqueous ethanolic extracts. We also used a biplot to graphically present data on the solvents and phenolic acids. As illustrated in Figure 4, two principal components (PC1 and PC2) account for $99.62 \%$ of the total variability. Besides, it shows the aqueous ethanolic extracts were closely linked to CGA, p-coumaric, salicylic acids while the aqueous extracts were associated with gallic and caffeic acids. In general, our results were compatible with the report of Angeloni et al. (2020), pointing out a greater extraction capacity of EtOH/water. And though a combination of water and ethanol enhances the extraction of most of the monitored phenolic acids, it reduces the extraction of gallic acid. The findings showed that both EtOH/water and water were efficient extractants for extracting bioactive phenolics in SCG, and importantly, these are environmentally benign solvents.

Chlorogenic acid is an important bioactive dietary phenolic compound produced by certain plants and is a major compound in coffee. It has been shown that this acid 
exhibits multiple health-promoting properties. For example, dietary consumption of CGA may lead to a remarkable reduction in systolic and diastolic blood pressure (Yamaguchi et al., 2008). Evidence also suggests that CGA in coffee affects body weight through inhibition of an accumulation of hepatic triglycerides(Shimoda, Seki, \& Aitani, 2006). In addition, CGA has been touted as having anticancer effects arising from its capacity to scavenge free radicals (Tajik, Tajik, Mack, \& Enck, 2017). The abundant presence of natural component like CGA in SCG helps highlight nutraceutical values of this byproduct and also suggests a utilization of this byproduct as an ingredient for food or nutraceutical productions.

TABLE 2. Phenolic contents ( $\mu \mathrm{g} / \mathrm{g}$ dry weight, $\mathrm{n}=3$ ) in the SCG extracts by different solvents

\begin{tabular}{|l|c|c|c|c|c|}
\hline \multirow{2}{*}{ Phenolics } & \multicolumn{3}{|c|}{ The present study (2021) } & \multicolumn{2}{c|}{ Angeloni et al. (2020) } \\
\cline { 2 - 6 } & $\begin{array}{l}\text { Retention } \\
\text { time, min }\end{array}$ & EtOH/water & Water & EtOH/water & Water \\
\hline Gallic acid & 4.93 & $11.8 \pm 0.5 \mathrm{~b}$ & $28.3 \pm 0.5 \mathrm{a}$ & 0.4 & 2.3 \\
\hline Chlorogenic acid & 10.22 & $840.4 \pm 32.1 \mathrm{a}$ & $300.0 \pm 22.3 \mathrm{~b}$ & 1184.1 & 1019.4 \\
\hline Caffeic acid & 12.30 & $98.2 \pm 1.1 \mathrm{~b}$ & $348.0 \pm 13.4 \mathrm{a}$ & 6.7 & 2.5 \\
\hline p-Coumaric acid & 16.06 & $91.1 \pm 4.0 \mathrm{a}$ & $7.1 \pm 0.3 \mathrm{~b}$ & 0.2 & 0.1 \\
\hline Ferulic acid & 17.00 & $123.8 \pm 1.0 \mathrm{a}$ & $72.8 \pm 9.5 \mathrm{~b}$ & 0.7 & 0.3 \\
\hline DA & 18.83 & $46.4 \pm 0.2 \mathrm{a}$ & $23.1 \pm 5.6 \mathrm{~b}$ & $\mathrm{NA}$ & $\mathrm{NA}$ \\
\hline Salicylic acid & 21.25 & $3.2 \pm 0.0$ & $\mathrm{NA}$ & $\mathrm{NA}$ & $\mathrm{NA}$ \\
\hline Cinnamic acid & 23.48 & $0.3 \pm 0.1 \mathrm{~b}$ & $0.6 \pm 0.1 \mathrm{a}$ & 0.1 & 0.1 \\
\hline Total phenolic acids & & $1215.3 \pm 36.3 \mathrm{a}$ & $779.9 \pm 36.0 \mathrm{~b}$ & $2987.8^{*}$ & $2133.1^{*}$ \\
\hline
\end{tabular}

Data are shown as mean \pm standard deviation. Samples were analyzed in triplicate. Values for the same phenolic acid followed by different letters indicate statistically significant difference $(\mathrm{p}<0.05)$.

NA: not detected or not reported

*: values were reported for a total number of 30 bioactive compounds in SCG.

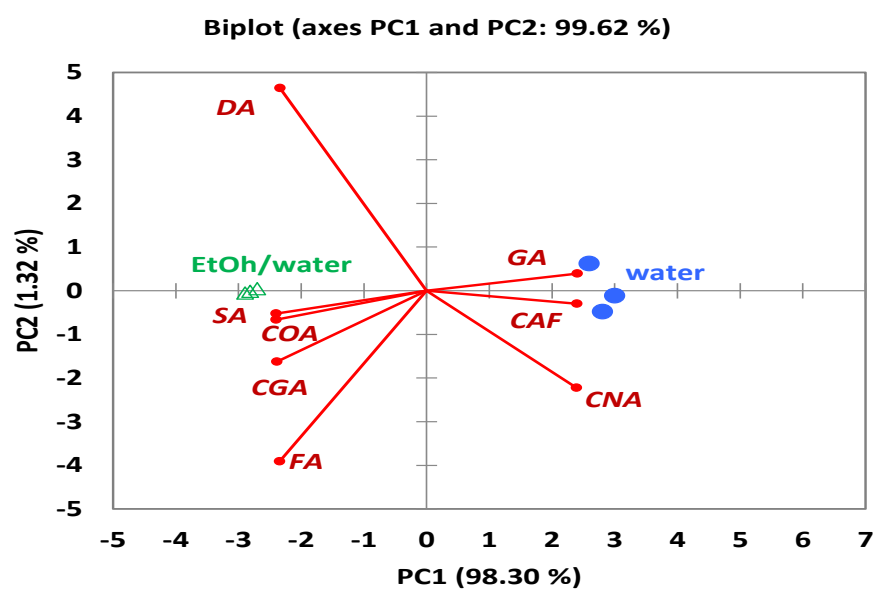

Figure 4. A biplot displaying the phenolic information on the SCG extracts. Abbreviations: gallic acid $(G A)$, chlorogenic acid $(C G A)$, caffeic acid $(C A F)$, pcoumaric acid (COA), ferulic acid $(F A)$ and cinnamic acid (CNA). 


\subsection{Fatty acids}

As shown in Table 3, the results demonstrated that the oil contained mostly linoleic acid $(61 \mu \mathrm{g} / \mathrm{g}$ oil), followed by palmitic acid $(47 \mu \mathrm{g} / \mathrm{g}$ oil). Besides, stearic and oleic acid are found to be present in the oil, at the levels of 10 and $15 \mu \mathrm{g} / \mathrm{g}$, respectively. The results are in agreement with prior research on Vietnamese coffee by Sung et al. (2015) (Sung, Jung, Sin, Kim, \& Wee, 2015). Linoleic acid is a polyunsaturated fatty acid found abundantly in vegetable oil. Our study showed that the level of this fatty acid in the SCG resembled that of corn oil (Dorni, Sharma, Saikia, \& Longvah, 2018).

SCG oil was known to contain high portion of glycerides that can be converted into biodiesel. A study revealed that polar components in SCG oil had a high free radical scavenging activity that can be an alternative to BHT in cooking oil (Hwang, WinklerMoser, Kim, \& Liu, 2019). Fatty acids in SCG oil are considered an inexpensive and suitable substrate for microbiological production of poly (3-hydroxybutyrate), an alternative to synthetic polymers (Obruca, Benesova, Kucera, Petrik, \& Marova, 2015).

TABLE 3. Fatty acid composition of the researched SCG

\begin{tabular}{|l|c|c|}
\hline Fatty acids $(\mu \mathrm{g} / \mathrm{g}$ oil) & The present study (2021) & Sung et al. (2015) \\
\hline Palmitic acid & 47 & 39.8 \\
Stearic acid & 10 & 8.5 \\
Oleic acid & 15 & 13.4 \\
Linoleic acid & 61 & 63.3 \\
\hline
\end{tabular}

\section{Conclusions}

In summary, our study revealed that SCG samples prepared from Vietnamese coffee were a good source of phenolic acids, such as chlorogenic, p-coumaric and ferulic acids. It also provided a characterization of phenolic profiles of SCG extracts by ethanol and water. Thereby, it demonstrated that the use of those environmentally benign solvents allows for a high extraction capacity of phenolics. In addition to phenolics, fatty acids, such as linoleic and palmitic acids, were shown to be present abundantly in the SCG oil. Our study has contributed information about phytochemicals of byproducts of coffee originating in Vietnam. We hope that our study will inspire more research into SCG and initiate more applications of SCG in the fields of food and nutraceuticals. From the perspective of sustainable production and consumption, the valorization of SCG could help increase coffee values, lower the disposal of the waste, reduce negative impacts on the environment and production cost and coffee product prices.

\section{Acknowledgments}

The authors would like to thank Van Lang University for supporting this research. 


\section{References}

Choi, B., \& Koh, E. (2017). Spent coffee as a rich source of antioxidative compounds. Food science and biotechnology, 26(4), 921-927.

Dorni, C., Sharma, P., Saikia, G., \& Longvah, T. (2018). Fatty acid profile of edible oils and fats consumed in India. Food Chemistry, 238, 9-15.

Getachew, A. T., \& Chun, B. S. (2017). Influence of pretreatment and modifiers on subcritical water liquefaction of spent coffee grounds: a green waste valorization approach. Journal of Cleaner Production, 142, 3719-3727.

Hwang, H. S., Winkler-Moser, J. K., Kim, Y., \& Liu, S. X. (2019). Antioxidant activity of spent coffee ground extracts toward soybean oil and fish oil. European Journal of Lipid Science and Technology, 121(4), 1800372.

Iriondo-DeHond, A., Garcia, N. A., Fernandez-Gomez, B., Guisantes-Batan, E., Escobar, F. V., Blanch, G. P., . . . del Castillo, M. D. (2019). Validation of coffee by-products as novel food ingredients. Innovative Food Science \& Emerging Technologies, 51, 194-204.

Kondamudi, N., Mohapatra, S. K., \& Misra, M. (2008). Spent coffee grounds as a versatile source of green energy. Journal of agricultural and food chemistry, 56(24), 11757-11760.

Martinez-Saez, N., García, A. T., Pérez, I. D., Rebollo-Hernanz, M., Mesías, M., Morales, F. J., ... del Castillo, M. D. (2017). Use of spent coffee grounds as food ingredient in bakery products. Food Chemistry, 216, 114-122

Ministry of Agriculture and Rural Development - Vietnam. (2020). Vietnam - the opportunity to become number 1 in the world coffee market. https://www.mard.gov.vn/en/Pages/vietnam--the-opportunity-to-become-number-1-inthe-world-coffee-market.aspx Accessed May 19, 2021

Mussatto, S. I., Machado, E. M. S., Martins, S., \& Teixeira, J. A. (2011). Production, composition, and application of coffee and its industrial residues. Food and Bioprocess Technology, 4(5), 661-672.

Obruca, S., Benesova, P., Kucera, D., Petrik, S., \& Marova, I. (2015). Biotechnological conversion of spent coffee grounds into polyhydroxyalkanoates and carotenoids. New biotechnology, 32(6), 569-574

Sampaio, A., Dragone, G., Vilanova, M., Oliveira, J. M., Teixeira, J. A., \& Mussatto, S. I. (2013). Production, chemical characterization, and sensory profile of a novel spirit elaborated from spent coffee ground. LWT-Food Science and Technology, 54(2), 557563.

Shimoda, H., Seki, E., \& Aitani, M. (2006). Inhibitory effect of green coffee bean extract on fat accumulation and body weight gain in mice. BMC complementary and alternative medicine, 6(1), 1-9.

Sung, H. M., Jung, H. J., Sin, J. S., Kim, K. M., \& Wee, J.-H. (2015). Skin whitening activity of supercritical fluid extract from spent coffee in B16F10 melanoma cell. Food science and biotechnology, 24(3), 1087-1096.

Tajik, N., Tajik, M., Mack, I., \& Enck, P. (2017). The potential effects of chlorogenic acid, the main phenolic components in coffee, on health: a comprehensive review of the literature. European journal of nutrition, 56(7), 2215-2244

Vu, D. C., Lei, Z., Sumner, L. W., Coggeshall, M. V., \& Lin, C.-H. (2019). Identification and 
quantification of phytosterols in black walnut kernels. Journal of Food Composition and Analysis, 75, 61-69.

World Atlas. (2016). Top Coffee Producing Countries. https://www.worldatlas.com/articles/topcoffee-producing-countries.html. Accessed May 18, 2021

Yamaguchi, T., Chikama, A., Mori, K., Watanabe, T., Shioya, Y., Katsuragi, Y., \& Tokimitsu, I. (2008). Hydroxyhydroquinone-free coffee: A double-blind, randomized controlled dose-response study of blood pressure. Nutrition, Metabolism and Cardiovascular Diseases, 18(6), 408-414.

Zengin, G., Sinan, K. I., Mahomoodally, M. F., Angeloni, S., Mustafa, A. M., Vittori, S., . . . Caprioli, G. (2020). Chemical Composition, Antioxidant and Enzyme Inhibitory Properties of Different Extracts Obtained from Spent Coffee Ground and Coffee Silverskin. Foods, 9(6), 713. 